\title{
Relaciones civiles-militares: una aproximación a los roles de las Fuerzas Militares en Latinoamérica y Colombia ${ }^{1}$
}

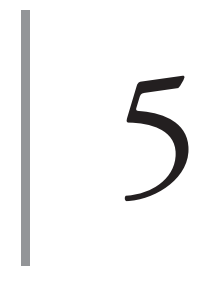

https://doi.org/10.21830/9789585318380.05

Sara Patricia Quintero Cordero ${ }^{2}$

Escuela de Aviación del Ejército

\section{Resumen}

Este capítulo analiza la relación entre fuerzas civiles y militares en Latinoamérica, haciendo énfasis en Colombia. Para ello, en primer lugar, se plantea una visión general de la problemática que ha generado una relación desigual y una distribución inequitativa del poder entre las autoridades civiles y militares. Posteriormente, se plantea un análisis histórico para identificar momentos claves que han orientado la relación entre las fuerzas civiles y las Fuerzas Militares, tanto en el plano internacional como en el territorio colombiano. En tercer lugar, se analiza cuál ha sido la evolución de las Fuerzas Armadas en Colombia, y cuáles han sido los principios y funciones que han orientado su desarrollo en las últimas décadas. Finalmente, se analizan propuestas concretas dirigidas a fortalecer un desarrollo integral de las Fuerzas Armadas, para que no solo se establezcan como garantes de la seguridad, sino también como actores claves en los procesos de toma de decisiones y en el desarrollo social y político del país.

Palabras clave: sociedad civil; Fuerzas Armadas; política; poder; posacuerdo; roles.

1 Este capítulo hace parte de los resultados del proyecto de investigación "Relaciones civiles-militares en Colombia: una aproximación a los roles de las Fuerzas Militares” del Grupo de Investigación en Ciencias Militares de la Escuela Militar de Cadetes "General José María Córdova” categorizado en B por Minciencias y con código de registro COL0082556. Los puntos de vista y los resultados de este artículo pertenecen al autor y no reflejan necesariamente los de las instituciones participantes.

2 Internacionalista. Magíster en Relaciones Internacionales (Universidad de Buenos Aires). Magíster en Seguridad y Defensa Nacionales (Escuela Superior de Guerra "General Rafael Reyes Prieto”). Investigadora de la Escuela de Aviación del Ejército Nacional (ESAVE). ORCID: https://orcid.org/00000002-9053-377X - Contacto: saraquinterocordero@cedoc.edu.co 


\section{Introducción}

El panorama reciente ha evidenciado un debilitamiento progresivo de los conflictos bélicos en Occidente, esto, debido al desarrollo de un enfoque cada vez más orientado hacia el fortalecimiento de la democracia y de una soberanía local mediada por organismos internacionales, que establecen mecanismos de control para enfrentar confrontaciones trasnacionales, generando como resultado no solo el desarrollo de nuevas políticas, que tienen como función garantizar la seguridad y el orden a través del acuerdo y el diálogo, sino también nuevos planteamientos y debates en torno al papel que deben desempeñar las Fuerzas Armadas en este panorama. Más específicamente, la cuestión radica en conocer cuáles son los tipos de relaciones que deben sostener los cuadros militares con la fuerzas políticas y económicas de los Estados.

De acuerdo con las apreciaciones de Pion-Berlin (2008), en la actualidad, la cuestión se ha reducido a entender si las Fuerzas Militares deben restringir sus funciones, y así evitar el desarrollo y perpetración de amenazas externas que atenten contra la seguridad nacional, o si deben proteger y ayudar a promover la estabilidad política de las naciones. Lo último equivaldría a decir que las Fuerzas Militares deberían tener algún tipo de participación política coordinada y legalizada que les permita incidir mediante la acción concreta en la estabilidad de una nación.

El planteamiento de este debate es sumamente relevante en la actualidad, pues se entiende que si las autoridades gubernamentales no orientan y definen estrategias concretas para promover el desarrollo de funciones de las Fuerzas Militares, que sean compatibles con los procesos de fortalecimiento democrático y de control civil, es posible seguir generando como resultado gastos innecesarios en los presupuestos de defensa, limitando las posibilidades de invertir en otro tipo de sectores que favorezcan la restructuración de la economía y la superación de inequidad y vulnerabilidad (Ciro y Correa, 2014, p. 7).

En este sentido, como explica Hunter (1996), las Fuerzas Militares y las fuerzas políticas deben implementar el desarrollo de alianzas estratégicas y procesos de relacionamiento que se retroalimenten constantemente, para atender la integridad territorial, promover procesos de mantenimiento de la 
paz en las fronteras, garantizar la seguridad internacional a partir de operativos claros de contrainsurgencia y prevención del tráfico ilegal. Asimismo, deben fortalecer la acción civil encaminada a evitar los conflictos internos y promover la inclusión social.

A pesar de estas propuestas, autores como Hunter (1996) y Moreno (2014) coinciden en que los gobiernos en Latinoamérica han utilizado como estrategia central la de mantener a las Fuerzas Militares ajenas a la esfera del poder y a los procesos de toma de decisión, limitando sus capacidades al control de la seguridad del Gobierno y de otros grupos de civiles.

De esta forma, siguiendo a Oehling (1967), se ha generado un proceso por medio del cual las Fuerzas Militares son compradas por el Gobierno para mantenerlas alejadas de la política y al mismo tiempo garantizar la seguridad de ciertos sectores de interés. Lo anterior implica como resultado, un mayor gasto en la defensa y una mayor asignación presupuestal para mejorar su modernización y promover su profesionalización, lo cual, como se ha dicho previamente, limita el gasto en proyectos sociales.

En conjunto, parece que esta estrategia, que se ha utilizado en Latinoamérica, resulta ser contradictoria y problemática, si se tiene en cuenta que, en la actualidad, en una época de democratización y reducción de los conflictos bélicos en la región, el enfoque central de los gobiernos debe ser el de reorientar las asignaciones presupuestales, enfocándose en la inversión social en lugar del fortalecimiento de las Fuerzas Armadas. Sin embargo, esta estrategia parece tener sentido para los gobiernos en sus intenciones de mantener alejados a los militares de las esferas del poder.

Teniendo en cuenta esta problemática, a continuación, se analiza concretamente la relación entre civiles y militares en Colombia, un país que posee características especiales debido a la emergencia social, política y económica asociada a un largo conflicto, el imperio del narcotráfico, y a los desafíos que se abren paso en medio de un periodo de concertación, reconciliación, reparación integral y recuperación progresiva de la democracia y el orden.

Para ello, en primer lugar, se plantea un análisis histórico que permita identificar momentos claves que han orientado la relación entre las fuerzas civiles y las Fuerzas Militares, tanto en el plano internacional como en el terri- 
torio colombiano. En segundo lugar, se analiza cuál ha sido la evolución de las Fuerzas Armadas de Colombia, y cuáles han sido los principios y funciones que han orientado su desarrollo en las últimas décadas. Posteriormente, se observan las problemáticas que limitan una relación de autonomía, distribución del poder y participación entre los poderes militares y los poderes civiles. Finalmente, se analizan propuestas concretas mediante las cuales sea posible fortalecer un desarrollo integral de las Fuerzas Armadas, para que no solo se establezcan como garantes de la seguridad, sino también como actores claves en los procesos de toma de decisión y en el desarrollo social y político del país.

\section{Contextualización sobre las autoridades civiles y militares en la actualidad}

El debate en torno a la participación política de las Fuerzas Militares ha sido matizado de una manera importante por Moskos (1981), quien expone que las Fuerzas Militares en todo el mundo, debido a la reducción de las guerras internacionales y a los nuevos enfoques políticos, han pasado a ser concebidas más como una ocupación que como una institución. Desde su perspectiva, cuando el Ejército se considera al interior de una sociedad como una institución, es porque presta un servicio basado en un conjunto de valores y deberes cuyo cumplimiento representa orgullo y compromiso con un país, de tal manera que sus actividades generan como resultado principal el honor. Las compensaciones se establecen a través de un sistema de méritos y beneficios sociales, pero no son monetarias. En este sentido, los miembros de una institución son generalmente vistos como personas que sirven a la sociedad de acuerdo con profundos principios de servicio que son comunes para todos los miembros.

Por otro lado, cuando el Ejército se considera como una ocupación, su desarrollo se establece no a través de valores sino de rasgos asociados con la economía del mercado. Se establece un esquema salarial, de tal manera que todas las recompensas son monetarias, y los objetivos no se orientan por el honor sino por logros que son medidos mediante indicadores. En este caso, temas como la demanda y la oferta son las que definen las acciones, agrupación 
y coordinación de las Fuerzas Militares. El enfoque económico y mercantilista, en este caso, ayuda a fortalecer el desarrollo de procesos de negociación entre los miembros del Ejército y las organizaciones gubernamentales. El punto básico de esta diferenciación, según Moskos (1981), es que tradicionalmente el Ejército ha tratado de mantense ajeno a los enfoques mercantilistas y organizacionales mediante los cuales se pasa de un enfoque institucional a uno ocupacional. Sin embargo, en medio de las nuevas características del contexto social, en el cual el Ejército es cada vez más sometido a los poderes civiles, hacer parte de un Ejército es considerado cada vez más como una ocupación que como una misión con enfoque institucional.

Ante esta situación, lo más importante es que en cada país se definan cuáles elementos institucionales y ocupacionales se deben establecer al interior de sus Fuerzas Armadas, partiendo para ello de una cuestión central: ¡el desarrollo y las funciones de las Fuerzas Armadas deben estar sujetas a un marco de análisis mercantil y económico?, o, en cambio, ¿deben responder al desarrollo de un servicio ético basado en el honor?

\section{Análisis histórico de las relaciones entre la esfera política y económica con la esfera militar}

La relación que existe entre las fuerzas civiles y las Fuerzas Militares tiene varios matices, dependiendo del periodo histórico del que se hable y de la orientación política de los Gobiernos de turno. Por ejemplo, en la época de la guerra fría (1947-1991), los países latinoamericanos adoptaron, en su mayoría, un conjunto de principios políticos orientados a contrarrestar las amenazas comunistas de la Unión Soviética y Cuba, en lo que se denominó la "Política de Seguridad Nacional", cuyo propósito era hacer frente a los nacientes movimientos de izquierda americanos, quienes, simpatizando con la ideología de la Unión Soviética, plantean posiciones opuestas a ideología política de Estados Unidos de América (Mateus, 2006).

De acuerdo con lo anterior, y a efectos de evitar las incursiones de la izquierda, varios países en Latinoamérica suscribieron con Estados Unidos el Tratado Interamericano de Asistencia Recíproca (TIAR), cuyo objetivo se 
centraba en defender el espacio geopolítico de los países suscribientes frente a las incursiones militares hechas por países socialistas. Si bien nunca se configuró alguna arremetida de relevancia para la seguridad del país norteamericano como líder del acuerdo, este tratado afectó fuertemente el sistema democrático del continente, pues la soberanía y autonomía de los países latinoamericanos se vio limitada frente a la intervención norteamericana (Mateus, 2006).

La adopción de ideologías anticomunistas a lo largo del continente delimitó el perfil de las Fuerzas Armadas en el América Central y del Sur, puesto que las políticas adoptadas por las Fuerzas Armadas para derrotar a los movimientos comunistas se enfocaban en eliminar la subversión y la disidencia, convirtiéndose en actores estratégicos en el cumplimiento de este objetivo. Esta visión general de un enemigo común especializó en formación y estrategia a los grupos militares, quienes tenían como único propósito el de eliminar a los grupos insurgentes.

En Colombia, hacia la segunda mitad del siglo XX, las guerrillas se consolidaron como un movimiento revolucionario armado opositor al Gobierno. Esta situación obligó a rediseñar los modos de operación del Ejército, pues las estrategias debían responder a un proceso planificado, mediante el cual se pudiese orientar el fortalecimiento de la estrategia militar, debido al carácter permanente de las amenazas y la violación continuada a la paz nacional y a los derechos humanos (Valencia \& Insuasty, 2011).

De este modo, el Ejército comenzó a formarse en escuelas en los Estados Unidos, lo que institucionalizó la idea de seguridad nacional que propendía por mantener la estabilidad del Estado como forma de garantizar el bienestar de la población (Santos et al., 2007). Así, frente a cualquier viso comunista, las Fuerzas Armadas tenían la posibilidad de tomarse el poder para mantener la soberanía. Con la caída del muro de Berlín, el 9 de noviembre de 1989, se daría fin a la Guerra Fría, y el comunismo sufriría un duro golpe representado en su imposibilidad de consolidarse como movimiento político en Occidente. Este acontecimiento evidenció el poderío económico de Estados Unidos y de algunos países europeos sobre naciones en vía de desarrollo como Colombia, hecho que hasta el día de hoy a significado una dependencia de Estados Unidos. Con los atentados del 11 de septiembre de 2001, el país norteame- 
ricano marcaría una tendencia mundial en temas de seguridad y protección, dando un giro a la formación y consolidación de los Ejércitos en el mundo.

El nuevo orden mundial generado a partir de este atentado modificó los temas de seguridad, pues se volcaron hacia la protección internacional y al control de movilidad de personas migrantes, obligando a las Fuerzas Armadas de las distintas naciones a especializarse en temas de tecnología, robótica e inteligencia militar, y proyectando la instrucción militar como una disciplina de estudio académico y científico. Con base en estos importantes cambios mundiales, desde el año 2011, el Ejército en Colombia ha fortalecido su planeación al tratar de anticipar las posibles amenazas futuras derivadas del contexto nacional. Mediante la conformación de distintos comités, y específicamente el Comité de Revisión Estratégica e Innovación (CRE-I), el Ejército impulsa iniciativas que soportan la visión de la institución, enfocándose en el sector defensa, la conducción de la guerra, y la capacitación según las áreas misionales de la entidad.

Ahora bien, ya que se ha planteado un análisis histórico, que permite entender las configuraciones que se han establecido en lo que respecta al papel de las Fuerzas Armadas en el mantenimiento y protección de la seguridad, es importante analizar el caso concreto de Colombia. En particular, se resalta que el panorama ha sido generalmente distinto al de los demás países en la región, no solo debido a las consecuencias del largo conflicto armado que ha afectado de manera estructural a las diferentes capas de la sociedad, sino también a causa de una serie de procesos históricos mediante los cuales se ha restringido, en gran medida, cualquier intento de acción política por parte de las Fuerzas Militares, además de mantener su subordinación total a las esferas del poder civil (Quintero, 2020).

Para soportar estas ideas es importante remitirse a la argumentación planteada por Moreno (2014), quien explica que en ningún otro país de Latinoamérica los militares son tan habitualmente desplazados del poder político. Para llegar a esta conclusión, el autor analiza tres momentos históricos específicos, mediante los cuales se puede observar la naturaleza altamente subordinada de las relaciones que se han establecido entre las Fuerzas Militares y civiles. El primer momento histórico se remite a la independencia de Colombia: 
La primera premisa que nos ayuda a comprender el fenómeno colombiano es sin duda un claro espíritu antimilitarista que se desarrolla en el país desde los primeros años de la Independencia. Desde ese momento ha hecho carrera en el país un rechazo a la institución militar y a los militares mismos en múltiples aspectos. Las élites civiles y económicas han colaborado en gran medida a alimentar este rechazo a la esfera militar. (Moreno, 2014, p. 337)

En particular, cuando Francisco de Paula Santander quedó al mando del gobierno de la ciudad de Bogotá, se comenzó a evidenciar un profundo antimilitarismo y un rechazo total a la posibilidad de que los militares gestionaran el desarrollo de los territorios liberados a través de la práctica política. En lugar de ello, fueron las élites económicas las que asumieron el control a partir del proceso de estructuración, lo que incluso pospuso la creación de un Ejército de carácter nacional.

A través de los acuerdos que se iban gestando entre las fuerzas civiles y las fuerzas económicas, se generaron hechos como que los líderes regionales tuvieran la capacidad de crear sus propios Ejércitos privados para garantizar la protección de sus intereses propios. Se evidencia así, desde el comienzo de la república, el desarrollo de un sentimiento antimilitarista que concebía al Ejército militar como una institución de clase baja que no tenía las facultades para competir por el poder.

El segundo momento histórico relevante se da en el siglo XIX, pues la ausencia de conflictos internos y de guerras fronterizas limita la necesidad de fortalecer y monopolizar las Fuerzas Armadas. Otro factor clave que limitó el desarrollo militar durante el siglo XIX fue la poca capacidad de centralización del poder, el cual se repartía entre las regiones, lo que no resultaba benéfico para la sociedad en su conjunto.

A comienzos del siglo XX se fundamenta el primer proceso de profesionalización del Ejército militar, a través de la influencia del Partido Conservador, el cual propone el desarrollo de una milicia de baja reputación dentro de la sociedad colombiana, un Ejército de alpargatas, el cual surge en medio de procesos como la resistencia de las élites civiles y el desarrollo del servicio militar obligatorio. En conjunto, estas situaciones derivan en un sentimiento generalizado de rechazo ante la institución militar. 
Finalmente, el tercer momento histórico se relaciona, precisamente, con la consolidación de los partidos políticos a mediados del siglo XIX, a través de un sentimiento marcadamente antimilitar, el cual, por ejemplo, permitió a los gobiernos liberales suprimir al Ejército entre 1853 y 1863. Se generó así la emergencia de un sistema político, en la medida en que los intereses que orientaban el desarrollo de los partidos se comenzaron a relacionar principalmente con alianzas para favorecer intereses económicos.

Cuando se comienza a propagar la guerra entre los partidos políticos, los militares son percibidos como contendores de dichos partidos. En este contexto histórico, la acción militar solamente tenía algún tipo de relevancia cuando se trataba de asegurar la defensa de los objetivos de alguno de los partidos en conflicto. En síntesis, a través del análisis histórico que se ha planteado, se puede observar que:

La constitución de Ejércitos de partidos políticos a lo largo del siglo XIX, la consolidación de un Ejército conservador a principios del siglo XX y las malas condiciones de los soldados en las primeras décadas de la profesionalización hacen que en el ciudadano regular no se construya la idea de un Ejército nacional, un Ejército que represente los verdaderos intereses de la nación (Moreno, 2014, p. 335)

De Arce y Témes (2003) fortalece esta argumentación al plantear que, históricamente, en ningún otro país de la región los poderes civiles han logrado encargarse no solo de la construcción y estructuración del Estado, sino además de orientar su acción y sus procesos de desarrollo. Esta estructura única y particular que se ha generado en Colombia ha promovido un aparato que anula cualquier intento de las Fuerzas Armadas por establecer iniciativas concretas de acción política coordinada.

En medio de este contexto, explica Andrade (2012), la única tarea que le ha sido asignada a las Fuerzas Militares por parte de la élite política y económica ha sido la de mantener el orden público, lo que resulta ser una tarea que demanda de todas las capacidades y fuerzas de la esfera militar, más aún en un país como Colombia, que ha sufrido durante más de cinco décadas las consecuencias devastadoras de un conflicto armado. De esta forma, los civiles remiten a los militares a un trabajo concreto mediante el cual se les asigna una identidad única que los limita y los restringe de manera indefinida. 
Otro factor importante que se puede observar a través del análisis histórico que se ha planteado, es que si bien en Colombia se han generado una serie de procesos y hechos que limitan la participación en política de las Fuerzas Militares, estas acciones se ajustan a las situaciones políticas del contexto social. En otras palabras, las Fuerzas Militares en Colombia no tienen participación política, pero su origen sí es politizado. Estas contradicciones resultan ser más evidentes cuando cualquier posibilidad de participación política ha quedado cercenada debido a otro hecho de carácter histórico y coyuntural: la propagación en las diferentes regiones del país de un conflicto armado que ha promovido la idea de que la única razón de ser de las Fuerzas Militares es la de luchar y derrotar a los enemigos del Estado.

De acuerdo con el análisis histórico que se ha planteado, es preciso observar cómo se han definido las funciones de las Fuerzas Armadas en Colombia y cómo se ha venido presentado un proceso de evolución en los últimos años, mediante el cual se ha ampliado su marco de acción, a pesar de que se siguen evidenciando importantes limitaciones en lo que respecta a su autonomía y participación.

\section{La evolución del papel de las Fuerzas Armadas en el territorio colombiano}

Los objetivos de las Fuerzas Armadas han sido establecidos por el Ministerio de Defensa de Colombia en la visión de la institución, según la cual las Fuerzas Armadas deben garantizar el control del Estado sobre la totalidad del territorio nacional, la seguridad de sus recursos naturales y la protección de los derechos de los ciudadanos, además de evitar agresiones externas y mantener la seguridad en un escenario de posacuerdo. El apoyo del Ejército a las autoridades civiles se ha orientado en Colombia al desarrollo de la Defensa del Estado, sector liderado por el Ministerio de Defensa. Por ello, es deber de estos organismos dar respuesta a los llamados y solicitudes que desde las autoridades civiles se presenten en el marco de emergencias nacionales o frente a la violación de derechos humanos a los pobladores protegidos.

Cabe tener en cuenta que desde finales del siglo XX las Fuerzas Armadas de Colombia se organizan en Comandos Conjuntos para el desarrollo de tareas 
en equipo, con la finalidad de combatir el terrorismo, el narcotráfico y, en general, todas las acciones de los grupos armados. Si bien las operaciones hechas a través de la Fuerzas de Tarea de Armas Combinadas fueron eficientes durante un tiempo, la evolución del conflicto armado obligó al Ejército colombiano a modificar sus operaciones (Atehortúa, 2009).

Estas modificaciones contextuales llevaron a revisar la doctrina militar del Ejército Nacional, entre otras, por las siguientes causas: 1) la entrada en vigencia de la sociedad de la información y las tecnologías de la información y la comunicación (Sullivan et al., 1998); 2) la necesidad de articular un lenguaje profesional único al interior de la institución, que se acompase con los demás Ejércitos del mundo (Rojas, 2014); 3) el imperativo de iniciar un proceso de estandarización de los conceptos militares para otorgarles la categoría de ciencia (Bassedas, 2006); y 4) la exigencia de garantizar el reconocimiento del marco jurídico que regula y orienta las operaciones militares.

Estos aspectos se han hecho más fuertes desde 2011, con la conformación del Comité de Revisión Estratégica e Innovación (CRE-I 2011), en el cual se retoman aspectos de tipo ideológico y militar implementados anteriormente por la Organización del Tratado del Atlántico Norte (OTAN). En particular, el CRE-I- 2011 está integrado por tres procesos básicos: operaciones, inteligencia y acción integral, los cuales buscan potenciar el efecto de las acciones estratégicas. Más adelante, en 2012, el Comité Estratégico de Transformación e Innovación (CETI 2012) se encargó de organizar la institución por sistemas y subsistemas, con el fin de definir las estrategias que promoverían las capacidades de las Fuerzas Armadas, invitando a los miembros de la institución a asumir una postura proactiva al enfrentar las problemáticas del contexto nacional, lo que produciría un cambio relevante en lo referente a la adopción de un enfoque centrado en anticipar los hechos que se debían enfrentar como organización.

Para el año 2013, la estrategia de cambio es liderada por el Comité Estratégico de Diseño del Ejército del Futuro (“Cedef 2013”), cuyo propósito es orientar a la organización para que opere en condiciones óptimas bajo una amplia variedad de condiciones. La metodología propuesta por este comité buscó reducir la incertidumbre y la complejidad de las operaciones, mediante 
la construcción de modelos de desarrollo estratégico diseñados para las intervenciones a corto, mediano y largo plazo, con miras a detallar la hoja de ruta de las intervenciones (Rojas, 2017).

Por otro lado, es preciso tener en cuenta que las dificultades derivadas de la imprevisibilidad del conflicto en Colombia han marcado varias etapas de transformación en las operaciones militares, debido a las particularidades del contexto y de la posición del enemigo que se quiere enfrentar. De acuerdo con Rojas (2017), se pueden identificar tres tiempos en los próximos diez años que marcan cambios importantes en la forma de operar de las Fuerzas Armadas:

1. 2014-2018: el Ejército se centra en una ofensiva militar fuerte para garantizar la seguridad y defensa nacionales.

2. 2018-2022: el Ejército se proyecta a nuevos escenarios en los cuales se establece una doctrina y lenguaje profesional común, que busca alinearse con los estándares internacionales en temas de inteligencia militar.

3. 2022-2030: el Ejército se enfoca en lograr su consolidación como Fuerza Multimisión y dar entrada plena al Ejército del futuro. En otras palabras, se busca que los miembros de las Fuerzas Armadas asuman roles específicos y a la vez múltiples, que les permitan frenar amenazas emergentes de una manera acertada.

La adopción de este proceso de formación y cambio institucional obedece a la tendencia de adoptar una doctrina que fortalezca el poder para aplicar la fuerza, a la vez que se optimiza la gestión de los procesos al interior de la institución, con la finalidad de cumplir de mejor manera la misión constitucional que le corresponde a las Fuerzas Armadas. Cabe tener en cuenta que esta visión es tomada de la doctrina militar estadounidense, la cual ha sido un referente para Colombia en temas de instrucción militar (Sullivan et al., 1998; Bonin \& Nagl, 2012).

En efecto, finalizando el 2015, el Ejército estadounidense terminó una reforma a su doctrina militar, la cual ha sido transferida a Colombia a través del proyecto "Damasco", cuyo propósito ha sido adaptar principios estratégicos militares a situaciones acordes con el contexto político, económico y 
social del país, tomando en cuenta factores geoestratégicos para la toma de decisiones sobre tomas e incursiones en determinados territorios. En medio del desarrollo de esta iniciativa, en el año 2015, se estructura el Plan Minerva, cuyo propósito es educar a los integrantes de las Fuerzas Armadas a través de trece (13) proyectos distintos, siendo el "Proyecto Damasco" el más alentador, al lograr su inclusión en el marco de proyectos del Departamento Nacional de Planeación.

La Doctrina Damasco busca reorganizar la forma de operación de las Fuerzas Militares, profesionalizando al personal y logrando de esta forma la participación internacional de las tropas, al lograr articular un lenguaje y conocimiento comunes, compartidos con los demás Ejércitos alrededor del mundo (Ejército de Colombia, 2016).

Este aspecto resulta fundamental para los futuros oficiales, quienes deben articularse a las necesidades del contexto mundial. En este sentido, la Doctrina establece tácticas y procedimientos que delimitan las funciones del Ejército y hacen un especial énfasis en la interacción con la población civil. Un punto que se destaca dentro de la Doctrina, consiste en que esta propende por garantizar la seguridad de la población civil, pues determina que las Fuerzas Armadas se deben concentrar en defender la seguridad territorial y el mantenimiento del orden fronterizo. A este respecto, Restrepo (2017) señala que

con las nuevas circunstancias del país, el Ejército tendrá mayor cercanía con la población y su actividad se desarrollará desde una perspectiva más social e integral. Esto reflejado en la posibilidad de satisfacer necesidades básicas de la población, por ejemplo, con la construcción de infraestructura social, económica y física. Este Ejército "constructor” podrá suplir falencias y vacíos institucionales y estatales a lo largo y ancho del territorio nacional. (p. 29)

De este modo, se busca que las decisiones estratégicas en materia militar tengan en cuenta los factores de ubicación y las particularidades geográficas del territorio, para determinar cómo influyen en el proceso de defensa nacional (Ortega, 2013). Desde el punto de vista militar, la geoestrategia, busca tomar decisiones con base en el estudio de las áreas geográficas en las que se pretende incursionar, teniendo en cuenta el espacio aéreo, terrestre, marítimo y demás zonas de amenaza que son determinantes a la hora de desplegar las estrategias 
militares (Ortega, 2013). Desde la perspectiva política, la geoestrategia se relaciona con el estudio de los escenarios que definen la formulación de políticas de defensa e incursión militar, siempre salvaguardando el bienestar de la población civil y la soberanía nacional.

Por otro lado, aunado a la colaboración estadounidense en la restructuración de las Fuerzas Militares en Colombia se encuentra también el Ejército chileno, que ha tenido una importante participación en la transformación doctrinal de las Fuerzas Armadas de Colombia, pues desde la suscripción, en 2011, del Acuerdo Marco de Cooperación entre los Ejércitos de Colombia y Chile, se inició la labor de reformar la doctrina militar nacional con la retoma de posturas de la "Doctrina Acorazada", técnica que, en palabras de Rojas (2017), consiste en:

La maniobra de armas combinadas se entiende como la habilidad, idoneidad y pericia que permite el uso de elementos de potencia de combate en una acción sincronizada, plenamente integrada, con el propósito de obtener y explotar la iniciativa, para derrotar fuerzas terrestres, obtener, ocupar y/o recuperar terreno y lograr ventajas físicas, temporales y psicológicas sobre el enemigo. Justamente, el Ejército chileno basa su doctrina acorazada en el modelo alemán, que se sustenta en la guerra de maniobra (velocidad y potencia de fuego) contra un objetivo débil estático o en constante movimiento [...] este concepto se denomina "mando tipo misión" a diferencia de la doctrina clásica estadounidense, que plantea la maniobra de acuerdo con plantillas doctrinales y se sustenta en la superioridad de medios. (p. 103)

La doctrina acorazada se enfoca en el equipamiento de blindaje fuerte y largo alcance, lo que permite misiones altamente móviles que atacan con profundidad al enemigo y que resisten ataques de alta artillería. Se diferencia de la acción motorizada en que esta última se refiere al transporte de personal y material logístico y no a la munición de blindaje. Una brigada acorazada es una unidad con amplia flexibilidad respecto de su organización, lo que le da la posibilidad de adaptarse a la misión requerida y convertirse en un equipo capaz de realizar operaciones prolongadas y continuas (Rojas, 2017). En Colombia, la combinación de estos elementos con la Doctrina Damasco configura la reestructuración del Ejército en los últimos años, de cara a constituirse en una organización con proyección a largo plazo, enfocado en análisis geopolíticos sobre el territorio, con la finalidad de mejorar la protección de la seguridad. 
El apoyo de las acciones de defensa a las autoridades civiles por parte de las Fuerzas Militares reviste unas características especiales, pues no son acciones propiamente ofensivas o defensivas, sino que se enfocan en salvar vidas, mejorar la calidad de vida de la población, proteger la propiedad pública y privada, y apoyar la recuperación social de los territorios intervenidos, sin emplear armas letales o acciones violentas (Sánchez et al., 2017). Dentro de las tareas puntuales de Apoyo de la Defensa a la Autoridad Civil (ADAC), se destaca la importancia de proporcionar ayuda en incidentes internos, apoyar en la atención de emergencias nucleares, químicas, biológicas o radiológicas que se presenten en el territorio, y brindar respaldo a los organismos civiles nacionales encargados de hacer cumplir la ley.

Se puede evidenciar, según el análisis de estas funciones, que las Fuerzas Armadas deben proyectarse en el país a través del desarrollo de temas estratégicos que les permitan ampliar su visión y perspectiva, al considerar al ciudadano como centro y justificación de sus operaciones, propendiendo por salvaguardar la integridad humana y el bienestar de las comunidades. Por medio de estas estrategias enfocadas en la protección de la población civil, se busca otorgar nuevos roles a la institución en el marco del posacuerdo. De esta manera, el escenario mediante el cual se ha promovido una ampliación de la visión de las Fuerzas Armadas en Colombia, busca ser un punto de apoyo en las labores de convivencia ciudadana, seguridad pública, gestión del riesgo, defensa nacional y desarrollo proyectivo (Ministerio de Defensa, 2016), todo ello como forma de reorientar las relaciones cívico-militares de una manera más eficiente.

Sin embargo, aumentar el rango de acción y las funciones de las Fuerzas Armadas no equivale a dotarlas de una mayor autonomía frente a los poderes civiles. Por el contrario, como explica Rojas (2014), parece ser que la ampliación de las funciones tiene como objetivo el de mantener el control de las Fuerzas Armadas y dirigir todas sus capacidades al cumplimiento de una serie de tareas importantes para la seguridad del país, enfocando su accionar en la práctica y el despliegue estratégico de acciones concretas en los territorios, pero que no se relacionan en ninguna medida con una mayor partición política, inclusión en escenarios de toma de decisión ni autonomía. 
Por lo tanto, teniendo en cuenta el análisis que se ha planteado sobre los objetivos, principios y evolución de las Fuerzas Armadas en Colombia, resulta clave entender la problemática que limita el desarrollo de una relación autónoma y de distribución equitativa del poder entre las Fuerzas Militares y el poder político.

\section{Problemáticas que afectan una relación de intercambio y distribución del poder político entre civiles y militares}

Los modelos de desarrollo del Estado, la calidad de relaciones confiables y transparentes entre el Gobierno y los ciudadanos, e incluso la efectividad de las relaciones internacionales dependen, en gran medida, del balance y equilibrio de poder que debe existir entre las fuerzas civiles y los estamentos militares (Cruz, 2015). Cuando se generan desbalances evidentes, y cuando, por ejemplo, los militares toman el control y tienen una incidencia directa y casi que incuestionable en las esferas de poder, en los procesos de toma de decisión y en la regulación de los asuntos de incidencia social y económica, se produce comúnmente la conformación de regímenes totalitarios que diluyen progresivamente la idea de democracia y limitan la participación política abierta (Rojas, 2014). Sin embargo, cuando lo anteriormente mencionado sucede, los militares acuden a una serie de procesos complejos, entre ellos la movilización de ciudadanos y el apoyo de ciertos sectores políticos. Estas situaciones no los eximen de enfrentarse a luchas armadas y confrontaciones directas, en las cuales los grupos militares tienen cierto apoyo de la población.

Sin embargo, siguiendo las apreciaciones de Atehortúa (2009), el desbalance es más común en el sentido inverso, cuando el poder se inclina a favor de una autoridad civil legítima, generando la respectiva sumisión incondicional de las Fuerzas Militares. En estos casos, como se ha visto a través del análisis histórico sobre Colombia, la labor de las Fuerzas Militares se reduce a garantizar la defensa de la sociedad y a mantener el orden interno. Si bien las consecuencias de promover un Estado con control y poder absoluto de las Fuerzas Militares puede resultar bastante nocivo para la democracia y los modelos de 
desarrollo, los mecanismos mediante los cuales se asegura el predominio civil también deben ser una preocupación de primer orden para los países democráticos.

Esta preocupación se debe a que cuando se presenta un enorme desbalance en el que prima el poder civil sobre el poder militar, las Fuerzas Militares, por lo general, carecen de un estatuto jurídico especial y se ven sometidas a los tribunales ordinarios (Atehortúa, 2009). Además, se generan gastos excesivos en la profesionalización de las Fuerzas Armadas, incluso cuando no hay situaciones de amenaza que pongan en peligro la seguridad de una nación, con la finalidad de mantenerlos alejados de la esfera política, mientras se potencia su poder defensivo y estrictamente militar (Palacios, 2003).

Evitar estas consecuencias afecta el balance natural del poder, explica Pion-Berlin y Martínez (2017), pues obliga a que los poderes civiles procuren que la profesionalización de los grupos militares no solamente se dirija a cuestiones de seguridad y defensa estratégica, sino también a permitirles un nicho de acción independiente de la política, lo que favorecería un modelo de balance y equilibrio, que en la actualidad resulta clave para mantener el fortalecimiento de los regímenes democráticos.

Haciendo un breve recuento, en Colombia, las relaciones entre los militares y la ciudadanía han operado desde mitad del siglo XX en un esquema en el que las Fuerzas Armadas se encuentran subordinadas al poder civil, pues se entiende que, bajo esta condición, se limita el poder militar frente a la posición de los ciudadanos (Dávila, 1998). Este modelo de operación ha generado tensiones, pues los intentos de politización de los militares se consideran una amenaza a su autonomía. A la vez, se asume que dotar de prerrogativas a un grupo con amplio poder, como lo es el de las Fuerzas Armadas, genera acciones que redundan en detrimento de la población civil (Lleras, 2003).

Como se puede apreciar, los debates sobre las relaciones entre población civil y militares en Colombia merecen una mirada especial, pues no basta con asumir la idea de que el cambio de un modelo totalitario a uno democrático evitaría las tomas de poder por parte de las Fuerzas Militares. La situación particular que implica la permanencia de los grupos insurgentes durante más de cinco décadas, y el accionar del narcotráfico como un flagelo común 
nacional, ha hecho que las estrategias militares busquen disipar la tensión entre los actores en conflicto, llevando a que los debates sobre esta relación contemplen otras dimensiones, en comparación con la situación de países como Argentina, Chile, Venezuela o Perú, que se han consolidado como naciones a partir de largos procesos dictatoriales.

El punto clave del análisis, según lo expresan Mares y Martínez (2014), consiste en comprender que las relaciones entre el poder civil y el poder militar dependen de las características de cada contexto, de las problemáticas sociales, de las amanezcas que atentan contra la seguridad y de los mecanismos que se han establecido para articular la diplomacia con la acción militar. En este sentido, para el caso colombiano, la dedicación casi exclusiva en acciones de contrainsurgencia y antinarcóticos hacen que las Fuerzas Armadas tengan funciones especiales para garantizar la soberanía del Estado. Por tanto, a nivel administrativo, las Fuerzas Armadas deben conservar su independencia y autonomía, lo que dista de lo acostumbrado en otros países de la región, en donde las situaciones de narcotráfico no son predominantes en el panorama nacional como amenaza constante a la seguridad (Quintero, 2020).

Si bien la misión encomendada a las Fuerzas Armadas es de suma importancia, puesto que se relaciona con el mantenimiento de la soberanía y el orden estatal, se resalta que la misión de sus integrantes es de carácter instrumental (Corte Constitucional, 30 de septiembre de 2003), pues son el soporte básico por medio del cual se garantiza la prevalencia de los derechos humanos. En otras palabras, la justificación de su existencia es inseparable de la construcción de la democracia y de la preservación de los derechos humanos (Corte Constitucional, 4 de diciembre de 1995).

Ahora bien, es importante orientar el análisis tomando como referencia un contexto de posconflicto. De acuerdo con la Corte Constitucional, Sentencia T-078 de 2013, la existencia de las Fuerzas Militares en un escenario de posconflicto debe orientarse a proteger a los ciudadanos y a garantizar su seguridad en tres facetas específicas:

1. Como valor constitucional, según lo consagrado en el artículo 2 de la Constitución Política, valor que es expresado en el aseguramiento 
y protección a la vida, la convivencia sana y demás derechos de goce y respeto a la autonomía.

2. Como derecho colectivo, pues a todos los pobladores les interesa el mantenimiento de la seguridad nacional para todos los miembros de la sociedad.

3. Como derecho fundamental de tipo individual que lleva a los ciudadanos a solicitar y recibir protección adecuada por parte del Estado, especialmente cuando se ve vulnerada la vida de una persona.

De acuerdo con lo anterior, es claro que tanto en el pasado como en la visión de futuro que orienta el desarrollo las Fuerzas Militares, su deber y razón de ser se han enfocado en garantizar la armonía de quienes habitan el territorio. Sobre el particular, Gómez y Correa (2014) señalan que,

en efecto, en el preámbulo, el constituyente, bajo la influencia de medio siglo de Estado de sitio, le indicó al Estado cuál debía ser su actitud ante el ciudadano y sus derechos, al señalar como fin de asegurar a sus integrantes la vida, la convivencia, el trabajo, la justicia, la igualdad, el conocimiento, la libertad y la paz. Aparece igualmente como uno de los fines esenciales del Estado: "asegurar la convivencia pacífica", a través de la protección de la "vida, honra, bienes, creencias, y demás derechos y libertades" de las personas residentes en Colombia, y de "asegurar el cumplimiento de los deberes sociales del Estado y de los particulares. (p. 41)

De acuerdo con el análisis planteado por Hunter (1996), en Latinoamérica generalmente se han venido utilizando dos estrategias para mantener controladas a las Fuerzas Militares. La primera es la estrategia subjetiva, mediante la cual la voluntad de los Ejércitos se mantiene subordinada al control del gobierno y de otro tipo de actores civiles. La segunda es la estrategia objetiva, por medio de la cual los militares se mantienen alejados de la esfera política a través de un incremento de la inversión en defensa, y de un proceso continuo de modernización y profesionalización de los miembros de la institución para que puedan responder a las amenazas.

Para sustentar esta idea, Hunter (1996) analiza el caso de tres países en la región, Argentina, Brasil y Chile, encontrando una serie de pautas y acciones comunes mediante las cuales se limita la participación política de los mili- 
tares o, por el contrario, se establecen mecanismos prácticamente ilimitados de expresión del poder militar. En Argentina se ha establecido un proceso que le ha permitido al Estado reducir su jurisdicción local, a través de la inclusión de políticas, en el gobierno de Carlos Menem, en las cuales se estableció un control objetivo al promover la defensa nacional y el mantenimiento de la paz internacional como las funciones centrales del Ejército argentino. Por tanto, se ha destinado un importante porcentaje del presupuesto para costear los salarios de las Fuerzas Militares del país, lo que ha favorecido también la posibilidad de mantenerlas alejadas de los escenarios de discusión política.

Algo similar ocurre en Brasil, en donde las problemáticas internas de seguridad, las amenazas que se generan en las fronteras y las emergencias sociales han hecho que las funciones de las Fuerzas Militares se concentren únicamente en el mantenimiento de mecanismos tradicionales de defensa. Finalmente, en Chile se observa una situación diferente, pues de los tres casos analizados es el país en el cual hay una menor constricción a la autonomía y participación de las Fuerzas Militares. Esta situación se debe a elementos característicos de la reciente historia chilena, puesto que Pinochet convoca un plebiscito en 1988 para continuar por ocho años más en el poder, sin embargo, aunque la ciudadanía respondió con un rotundo no, el tema de esta participación ciudadana estaba sujeta en la Constitución chilena que promulgaba la realización de este instrumento para legitimar su estancia en el poder político, y a pesar que para su momento el dictador era un figura fuerte, la oposición vio la oportunidad de establecer una transición a la democracia y fue lo que finalmente sucedió, no obstante, las fuerzas militares chilenas estuvieron en dicho proceso que conllevo a un acoplamiento con la población civil a pesar de la representación político militar de Pinochet en la vida de los chilenos.

Sin embargo, a pesar de un fuerte proceso de transición democrática que ha tenido como objetivo reducir la incidencia militar en la esfera política, en este país se ha logrado mantener una gran fuerza económica por parte del Ejército. Esta autonomía ha permitido a los militares cierto grado de libertad para decidir cuáles son sus misiones y funciones, las cuales se han enfocado principalmente en la modernización de estrategias, técnicas y equipos que ayuden a garantizar la defensa ante amenazas de tipo internacional. 
El análisis sobre estos tres países permite comprender las dimensiones de tres relaciones problemáticas entre las fuerzas civiles y políticas. Por un lado, en Argentina son los grupos civiles los que toman las decisiones y definen los cursos de acción, sin tomar en cuenta al Ejército, y utilizándolo simplemente con fines instrumentales. En Brasil, por otro lado, ocurre un caso similar, pues las fuerzas civiles definen las funciones y concretan las limitaciones de las Fuerzas Militares (caso que, según el análisis previo que se ha planteado, es similar a lo que ocurre en Colombia). Finalmente, en Chile se ha evidenciado un panorama contrario, en el cual la fuerza y el poder militar es mucho más autónomo, debido a cuestiones históricas, las cuales le permiten al Ejército contar con la libertad de definir sus funciones e incluso incidir sobre temas presupuestales.

El punto que plantea Hunter (1996) a partir de este análisis, se centra en que en los casos reseñados se evidencia un poder desequilibrado entre las fuerzas civiles y militares. Ante esta situación, lo ideal es que hubiera una distribución equitativa mediante la implementación de escenarios de participación y colaboración, por medio de los cuales sea posible generar estrategias de desarrollo local, defensa y seguridad a partir de un enfoque que combine e integre los conocimientos, capacidades y experiencias tanto del Ejército como de las esferas civiles.

En Argentina, por ejemplo, se debe generar un proceso de apoyo y colaboración entre autoridades civiles y militares. En Brasil, es preciso mejorar lo que tiene que ver con la definición de los roles de las Fuerzas Militares, especificando sus misiones en escenarios que no únicamente se relacionen con la seguridad internacional sino también con lo local. En Chile, se necesita tratar de controlar, en cierto grado, la libertad del Ejército, a través de la implementación de mecanismos de control subjetivo y objetivo, con la finalidad de evitar abusos de poder. A este análisis se le puede sumar el caso de Colombia, en el cual una recomendación central para promover un mayor equilibrio de poder consiste en mejorar los procesos de capacitación y formación de las Fuerzas Armadas en temas asociados con las necesidades, metas y desafíos relacionados al desarrollo social de toda la nación.

Es claro que el diseño de un proyecto mediante el cual se promuevan factores como la participación y la autonomía del Ejército debe orientarse a 
través de estrategias de formación integral, con el fin de que las funciones de los miembros de las Fuerzas Armadas vayan más allá de la acción directa, a través de incursiones en las que deban enfrentarse con pobladores y grupos armados para defender la seguridad del país.

Como lo explica Hunter (1996), el liderazgo y la profesionalización deben ser el norte que guíe los procesos de formación al interior de las Fuerzas Armadas, con el fin de garantizar el mantenimiento del orden constitucional, con prevalencia del respeto de los derechos humanos. En este sentido, es importante especificar con mayor detenimiento cuáles son los principios que se deben orientar para promover un mayor equilibrio en la detención y expresión del poder entre autoridades civiles y militares.

\section{Análisis enfocados en promover una relación de mayor autonomía entre las Fuerzas Militares y las fuerzas civiles}

El punto central para que las Fuerzas Militares puedan tener una mayor presencia en los espacios de toma de decisión, y de esta manera generar una distribución equitativa del poder entre el poder civil y el militar, es el de promover el desarrollo de nuevas capacidades, conocimientos y habilidades para las Fuerzas Militares, que les permitan a estas seguir atendiendo a las necesidades de defensa nacional, pero también promover estrategias de atención a las necesidades de la población, iniciativas de desarrollo sostenible y promoción de acciones cívicas que no se basen únicamente en el uso de la fuerza, sino también en la planeación, la estrategia y el análisis integral de los problemas. Esto, en el caso en el cual la balanza se ha inclinado a favor de las élites políticas y las autoridades civiles, mientras que en aquellos casos en los cuales el Ejército goza de ciertas prerrogativas, que pueden derivar en abuso del poder, se deben establecer mecanismos que limiten, en cierta medida, su autonomía por medio de la injerencia del Estado (Hunter, 1996).

De acuerdo con Sullivan, Harper y Mallarino (1998), mejorar la autonomía de las Fuerzas Armadas depende también de mejorar continuamente sus capacidades. Por tanto, es preciso formar líderes integrales al interior de las 
Fuerzas Armadas y organizar eficientemente grupos que respondan de manera efectiva a las eventuales amenazas de guerra. Es a partir de dichas amenazas que las misiones militares se han rediseñado, exigiendo acciones más flexibles y multimisión, que den el apoyo esperado a la sociedad civil como parte de su reconocimiento institucional.

Estas adaptaciones, en términos de estrategia y modernización, responden a la naturaleza del enemigo común y el deber de ajustarse a los acuerdos internacionales que, en materia de derechos humanos y derecho internacional humanitario, debe cumplir Colombia como miembro de la comunidad internacional y garante de la seguridad de sus ciudadanos. Mejía (2009) hace referencia a la importancia de reconocer el poder del enemigo y ajustar las estrategias militares a las necesidades identificadas, comenzando por tomar en cuenta que

el enemigo es fuerte, porque el Estado ha sido débil durante más de cuatro décadas; que no se encuentra derrotado ni militar ni políticamente; que además se halla totalmente robustecido por sus finanzas ilícitas; que se despliega nacional e internacionalmente; que es altamente móvil; que utiliza métodos terroristas ( $\tan$ antiguos como el mismo arte de la guerra), que se adecúa a nuestras actuaciones, que se mueve en un territorio desconocido para la mayoría de nuestros hombres y que combina diferentes formas de lucha; en fin, que al enemigo así se le catalogue como simple terrorista cree firmemente en una guerra popular prolongada para tomarse el poder. (Mejía, 2009, p. 294)

De acuerdo con lo anterior, las Fuerzas Armadas deben centrarse en rediseñar y mejorar el arte de sus operaciones, manteniendo siempre la visión de protección a la población civil como eje central de todas sus operaciones, para lo cual deben cubrir todos los frentes para así contar con la capacidad de dar al país una cobertura estratégica (Ciro y Correa, 2014). Si bien podría asumirse como tarea sencilla el deber de adaptación al contexto y actualización estratégica dentro de la organización militar, las Fuerzas Armadas en Colombia enfrentan situaciones complejas en donde vislumbrar las amenazas futuras no es una labor sencilla.

El proceso de transformación de las Fuerzas Armadas busca ajustarse a un escenario de posconflicto en el que los derechos de los ciudadanos y el mantenimiento de la soberanía estatal son los ejes sobre los que se articulará el rol del 
Ejército. El diseño de un modelo que transforme la institución debe propender por lograr mejoras estratégicas en todos los campos de apoyo gubernamental que se requiera en la implementación de los acuerdos de paz, especialmente en el mantenimiento de la seguridad humana como derrotero nacional.

En cumplimiento de lo anterior, la transformación de las esferas militares busca responder a los desafíos de una nueva realidad, en la que la gestión del conocimiento obedece a las estructuras de la sociedad de la información, la tecnología y el compromiso internacional del Estado en la salvaguarda de los derechos humanos, a la luz de los acuerdos internacionales que ha suscrito previamente (Gómez \& Correa, 2014).

La transformación de las Fuerzas Armadas en una Fuerza Multimisión busca que la planeación estratégica, liderada desde el Ministerio de Defensa, obedezca a la naturaleza de un Estado Social y Democrático de Derecho, de modo que la adaptación y la reinvención atiendan a las necesidades que producto del contexto y del escenario posterior al acuerdo surjan en el país. En este sentido, el rol del Ejército del futuro debe orientarse según la apropiación de procesos, estructuras, y un andamiaje académico y operacional que se ajuste a las exigencias de la sociedad, con el objeto de no cometer los errores que, en el pasado, en algunas experiencias de combate, le han generado muchas veces una injustificada "mala fama" a nivel nacional. Las fortalezas requeridas en la actualidad deben acompasarse con una responsabilidad ética con el conocimiento y cimentarse en el respeto al otro.

En cumplimiento de lo anterior, las Fuerzas Militares lideran el monopolio legítimo de la fuerza como una de las manifestaciones del poderío del Estado como ente, por ende, estas deben construir su estrategia y desarrollar su acción basadas en el principio de legalidad propio del Estado de Derecho; con base en esta premisa, el Estado Constitucional rechaza cualquier forma de abuso del poder por parte de sus instituciones, siendo la Carta Política la garante del mantenimiento de dicho orden. Sobre el particular, la Sentencia C-179 de 1994 señala:

El Estado de derecho es una técnica de organización política que persigue, como objetivo inmediato, la sujeción de los órganos del poder a la norma jurídica. A la consecución de ese propósito, están orientadas sus instituciones que, 
bajo esta perspectiva, resultan ser meros instrumentos cuya aptitud y eficacia debe ser evaluada según cumplan o no, a cabalidad, la finalidad que constituye su razón de ser. (Corte Constitucional, 1994).

Lo preceptuado en el fallo anteriormente citado, explica Bassedas (2006), significa que el alcance y el despliegue del poder de las Fuerzas Militares debe sujetarse a la obediencia de los mandatos constitucionales, específicamente al cumplimiento del principio de legalidad y al de subordinación a las autoridades civiles, en aras de garantizar la protección a los derechos humanos y el cumplimiento de las disposiciones en materia de derecho internacional humanitario. En efecto, el Ejército como entidad perteneciente al aparato estatal, tiene asignadas dos labores sustanciales que justifican su importancia dentro de este andamiaje institucional: 1) son las únicas con potestad de manejo del monopolio de las armas y el uso de la fuerza; y 2) son las encargadas de cumplir con los fines esenciales de defensa y seguridad de la nación, así como de garantizar el orden jurídico constitucional del país (Cruz, 2015).

Para sintetizar el análisis que se ha planteado, se puede decir que existen relaciones asimétricas de poder entre las fuerzas civiles y las militares en los gobiernos de Latinoamérica. Si bien el análisis se ha centrado en el caso colombiano, se evidencia que en países como Argentina, Brasil y Chile se han presentado también problemáticas a través de las cuales se ha generado una distribución desigual del poder. Ante esta situación, el enfoque debe ser el de no privilegiar a ninguna de las dos autoridades, sino promover enfoques colaborativos y de participación. Retomando las apreciaciones de Hunter (1996), la estrategia central en los gobiernos de Latinoamérica debe ser la de fomentar la preparación y el profesionalismo de las Fuerzas Militares, utilizando para ello menos recursos que pueden, en cambio, ser utilizados en la satisfacción de otras necesidades que reclamen urgentemente las comunidades.

Para ello, es necesario dejar de concentrarse únicamente en las funciones de las Fuerzas Militares en lo que respecta a la defensa nacional. Lo que resulta fundamental, teniendo en cuenta la reducción de las guerras y los conflictos sociales armados, además de la necesidad de utilizar el presupuesto de los gobiernos en otros rubros relacionados con el desarrollo social y la superación de la vulnerabilidad. Además de ello, otra estrategia consiste en forta- 
lecer a la Policía y favorecer el desarrollo de organizaciones no militares que se encarguen de detener el crimen y mantener el orden social, para darle así la posibilidad a las Fuerzas Militares de especializarse en otros campos, como actividades contra narcóticos, operaciones de inteligencia y fortalecimiento de una naciente democracia institucional.

Lo más importante, explica Hunter (1996), es que se tomen decisiones concretas en cada país para que las Fuerzas Militares no permanezcan en una especie de limbo, sin una misión legítima, sin un objetivo claro relacionado con el mejoramiento de las condiciones de vida de la nación. Es preciso dejar de replicar modelos que circunscriben las actividades y capacidades de los militares únicamente en procesos de activismo e intervencionismo local como medio para garantizar la seguridad.

Por otro lado, también es clave que en este momento crucial de la historia en Latinoamérica, caracterizado por una compleja emergencia social que ya no es producto del conflicto y de las guerras, sino de situaciones de vulnerabilidad, corrupción, pobreza e inequidad, los gobiernos puedan aprovechar los nuevos retos, oportunidades y procesos de transformación que se presentan, para reorientar la labor y las funciones militares, utilizándolas no como grupos que se deben mantener ajenos a los procesos de participación política (lo que implica gastos elevados y muchas veces injustificados en defensa), sino como una institución con principios y valores que puede aportar de manera considerable a la solución de las problemáticas que amenazan tanto el bienestar como el desarrollo social y local.

Lo anterior implica el desarrollo de un control objetivo sobre las Fuerzas Armadas, el cual, como se explicaba previamente, representa el desarrollo un proceso continuo de modernización y profesionalización por parte de los miembros de la institución. Sin embargo, esta modernización no solo es clave para que las Fuerzas Militares puedan responder a las amenazas de tipo internacional, sino para que también tengan la posibilidad de mejorar sus capacidades de participación en procesos de diálogo y mecanismos consensuados de toma de decisiones.

En conjunto, estas estrategias resultan claves en un escenario de posconflicto como el que atraviesa Colombia, en el cual se enfrentan retos 
importantes para promover escenarios de reparación integral y fortalecer la articulación efectiva de un trabajo conjunto, que promueva el desarrollo continuo de las capacidades de las comunidades. En este contexto, el gasto del presupuesto debe ser planteado para que, en lugar de seguir costeando inversiones significativas en la defensa nacional y en el fortalecimiento militar para atacar y contratacar, se invierta en estrategias de recuperación territorial y de reconciliación social, en las cuales el Ejército puede cumplir una función importante de mediación y de facilitación de iniciativas y procesos de reconstrucción social y económica.

\section{Referencias}

Andrade, O. (2012). Relaciones cívico-militares en Colombia: apuntes para un estado del arte. Observatorio de Construcción de Paz. Revista análisis internacional, 1(6), 145171.

Atehortúa, A. (2009). Construcción del Ejército Nacional en Colombia, 1907-1930: reforma militar y misiones extranjeras. Carreta Editores.

Bassedas, P. (2006). La seguridad internacional después de la Guerra Fría ¿Avanzando hacia una doctrina de seguridad humana? Fundación CIDOB, (100), 1-7.

Bonin, J., \& Nagl. J. (2012). The TRADOC Doctrine Publication Program.

Colombia, Corte Constitucional de Colombia. (1994). Sentencia C-179-94. MP. Gaviria Díaz, C.

Corte Constitucional de Colombia (4 de diciembre de 1995). Sentencia C-578-95. M. P. Cifuentes Muñoz, E.

Corte Constitucional de Colombia (30 de septiembre de 2003). Sentencia C-872-03. M. P. Vargas Hernández, C. I.

Corte Constitucional de Colombia. (2013). Sentencia T-078-13. MP. Mendoza Martelo, G. E.

Ciro Gómez, A. R. y Correa Henao, M. (2014). Transformación estructural del Ejército colombiano. Construcción de escenarios futuros. Revista Cientifica General José Maria Córdova, 12(13), 19-88.

Cruz, E. (2015). Relaciones cívico-militares, negociaciones de paz y postconflicto en Colombia. Criterio Jurídico Garantista, 8(13), 12-41.

Dávila, A. (1998). El juego del poder. Historia, armas y votos. Ediciones Cerec.

De Arce y Témes, A. (2003). Colombia. Las relaciones entre la sociedad civil y militar: hacia un entendimiento necesario. En Ministerio de Defensa e IEEE (Instituto Español de Estudios Estratégicos) (Eds.). Presente y futuro de las relaciones cívico-militares en Hispanoamérica (pp. 22-56). Cuadernos de Estrategia 123. Madrid: Ministerio de Defensa. https://dialnet. unirioja.es/descarga/articulo/792917.pdf. 
Ejército de Colombia. (2016). Doctrina Damasco MFE 1-01. Fuerzas Militares de Colombia.

Gómez, A., \& Correa, M. (2014). Trasformación estructural del Ejército colombiano. Construcción de escenarios futuros. Revista Cientifica General José Maria Córdova, 12(13), 19-88.

Hunter, W. (1996). State and soldier in Latin America. Redefining the Military's Role in Argentina, Brazil, and Chile. Peaceworks, (10), 1-57.

Lleras, A. (2003). Las Fuerzas Armadas. En F. Cepeda (Ed.), Las relaciones cívico-militares en tiempos de conflicto armado (pp. 329-342). Fundación Ideas para la Paz.

Mares, D., \& Martínez, R. (2014). Debating civil-military relations in Latin America. Sussex Academic Press.

Mateus, J. (2006). Reflexiones desde la academia sobre las relaciones cívico-militares. Revista de Relaciones Internacionales, Estrategia y Seguridad, 1(1), 9-16.

Mejía, J. (2009). Sin eufemismos: conflicto y paz en Colombia. Editorial Temis.

Moreno, J. (2014). Relaciones cívico-militares en Colombia: supremacía y control de los partidos políticos sobre la organización militar. Revista Cientifica General José Maria Córdova, 12(13), 333-352.

Ministerio de Defensa. (2016). Areas misionales. Plan Estratégico del Sector Defensa y Seguridad.

Mosko, C. (1981). From institution to occupation: Trends in military organization. Armed Forces \& Society, 4(1), 41-50.

Oehling, H. (1967). La función política del Ejército. Instituto de Estudios Políticos.

Ortega, R. (2013). Valorización geoestratégica de los Estados. Escenarios actuales, (1), 5-20.

Palacios, M. (2003). Entre la legitimidad y la violencia: los tres países de Colombia. En M. Cárdenas (Coord.), La construcción del posconflicto en Colombia (pp. 75-82). Fondo Editorial Cerec.

Quintero, S. (2020). La inseguridad colectiva: respuestas a lo inesperado. Revista Cientifica General José María Córdova, 18(31), 547-564. http://dx.doi.org/10.21830/19006586.615

Pion-Berlin, D. (2008). Militares y democracia en el nuevo siglo: cuatro descubrimientos inesperados y una conclusión sorprendente. Nueva Sociedad, (213), 50-63.

Pion-Berlin, D., \& Martínez, R. (2017). Soldiers, politicians, and civilians: reforming civil-military relations in democratic Latin America. Cambridge University Press.

Restrepo, J. (2017). La Academia y Damasco. Experticia Militar, (1), 6-11.

Rojas, A. (2014). Principales debates sobre relaciones civico-militares en Colombia. http://www. codhes.org/-codhes/images/Articulos/Principales_debates_sobre_relaciones_civico.pdf

Rojas, P. (2017). Doctrina Damasco: eje articulador de la segunda gran reforma del Ejército Nacional de Colombia. Revista Cientifica General José María Córdova, 15(19), 95-119.

Sánchez, M., Barón, J., Yara, Y., \& Martínez, M. (2017). La seguridad humana en la Doctrina Damasco: un eje de transformación hacia el Ejército del futuro. Brújula. Semilleros de investigación, 5(10), 6-17.

Santos, J., Mejía, R., Mesa, J., \& Díaz, F. (2007). Historia militar del Ejército de Colombia. Centro de estudios históricos del Ejército. 
Sullivan, G., Harper, M., \& Mallarino, G. (1998). La esperanza no es un método: lo que la gerencia de hoy puede aprender del proceso de reingeniería del Ejército de los Estados Unidos. Norma.

Valencia, J., \& Insuasty, A. (2011). Evolución de las estrategias de guerra en Colombia: ¿Cómo han evolucionado las estrategias de guerra utilizadas por el Ejército colombiano en la historia de Colombia, desde 1930 hasta 2006? El Ágora USB, 11(1), 67-88. 